\title{
Mini U Brochures: Advertising Social Exclusion at a Post-secondary Institution, Canada?
}

\author{
JuSung $\operatorname{Kim}^{1 *}$ and jay johnson ${ }^{2}$
}

\begin{abstract}
The purpose of this research is to analyze visuals and texts from the three 2015 and 2016 Mini U (sport, recreation, and academic programs for young people) brochures at a post-secondary institution, Canada. Semiotics of the brochures is analyzed first and content analysis follows. The findings of this study are: (1) an overall impression of visuals from the brochures appears a dominant imagery of whiteness; (2) the techniques for taking pictures (e.g., size, clarity, colour, lay out, and representation of certain images) in the brochures make White figures more visible than non-White figures; (3) $87 \%, 88 \%$, and $89 \%$ of figures of children and youth are White, and $87 \%$, $94 \%$, and $100 \%$ of the Mini U program leaders are White; (4) the offered Mini U programs tend to be designed for White-centred programs (e.g., hockey, ice programs); and (5) the images of whiteness in the brochures seemly reflect institutional social exclusion and racism on Canadian campus. A socially just and sustainable campus can be possible by changing the publication practice of Mini U brochures as a small step.
\end{abstract}

Key words: racism, whiteness, exclusion, higher education, visuals, multiculturalism, sustainable diversity

\section{Introduction}

Since the inception of the multiculturalism policy in 1971 (i.e., equal celebration of religious, racial/ethnic, and cultural heritages and identities), Canada's higher educational institutions have struggled to promote the racial diversity and inclusion of campus members across the country. However, tensions, intolerance, and ignorance against racialized groups are seemly still present across Canadian campuses in spite of social justice and anti-racism movements. Canadian campuses cannot escape the legacies of social injustices, racism, and whiteness like the U.S. ones (Douglas \& Halas, 2013; Ross \& Edwards, 2016; Tator \& Henry, 2009). Both explicit and subtle forms of racism as a kind of social injustices occur in North American campuses tokenizing minority students, teachers, and staff (Baffoe, Asimeng-Boahene, \& Buster, 2014; Harwood, Choi, Orozco, Browne, \& Mendenhall, 2015). Racial discrimination (e.g., admission, hiring, promotion, governance, research, or curriculum against visible minorities) pervades in Canadian universities (Baffoe et al., 2014; Douglas \& Halas, 2013; Henry \& Tator, 2009; Tator \& Henry, 2010). The everyday reality of racism has been submerged and continues to exist in invisible ways.

Several actions have been held to eliminate racism across Canadian campuses. Some Canadian universities have started to take actions against racism towards improving the fair treatment of racialized campus members by implementing social

\footnotetext{
${ }^{1}$ Applied Health Sciences and Kinesiology and Recreation Management, University of Manitoba, Canada.

2 Faculty of Kinesiology and Recreation Management, University of Manitoba, Canada.

*Corresponding author.
} 
justice and anti-racism strategies (Henry \& Tator, 2006; 2009; Tator \& Henry, 2010). Although continuous efforts to eradicate racism and to nurture cultural diversity have been made, "more universities and colleges become places that define, stereotype, and treat people in line with their skin pigment or the origins of their ancestors" (Campbell, 2012, p. 389). It is conceivable that such numerous social inequalities and anti-racism movements represent how racism engrains in Canadian campuses and society.

Like the other aspects of Canadian campuses, the marketing materials of Mini University programs (Mini U) for diverse young customers are under severe scrutiny. Mini $U$ has offered sport, recreation, and academic programs for young people aged between 4 and 16 years old through the University of Manitoba (UM), Canada for 39 years.

\subsection{Racism in Modern Society}

Despite anti-racism and human right movements and transnational immigration via globalization, racism is on the rise across our communities and nations (Clark et al., 2014; Guo, 2015; Harrison, 2013; Harwood et al., 2015; Mensah \& Williams, 2015; Smith, 2015). It was predicted by many people that both racism and discrimination would be left behind as an old legacy post World War 2 (Satzewich, 2010). Unlike the optimistic predictions, racism is ubiquitous and exists regardless of whether we sense it or not, and racism intersects with other social markers including gender, class, or age. Integrating justice in development studies, Abdelhameed (2016) argues that social justice includes "provision of non-discrimination on the basis of race, sexual orientation, ethnicity, caste, religion, or national origins" (p. 48). Dependent on cultures and locations, the forms of racism vary in scope from ethnic cleansing, cultural genocide, sport related-, employment-, online/media-, health-, and school racism, racial slur and graffiti, and racial profiling by police (Bradbury, 2011; Mensah \& Williams, 2015; Satzewich, 2010; Smith, 2015). All in all, racism matters because it survives everywhere in our current life.

The current forms of racial discrimination in modern society appear subtle and unintentional. Instead of explicit and forced racism, insidious, persuaded, and civilized modes of social control mechanisms (i.e., invisible forms of racism) (Clark et al., 2014; Douglas \& Halas, 2013; Harwood et al., 2015; Ross \& Edwards, 2016; Satzewich, 2010) are inevitable. That is, racism has become sophisticated and submerged into our daily life unconsciously, so it is exercised silently and implicitly rather than loudly and explicitly due to the impact of multicultural and civil right movements. Unlike the previous times, contemporary racial manifestations and expressions are most often invisible to perpetrators so that racism even pervades in many intricate forms (Clark et al., 2014). As a Janus face of racism, whiteness has been continuously evolving accordingly, and the meaning of whiteness is complex in that it embraces concepts of hegemony and power (Frankenberg 1997 as cited in Baffoe et al., 2014), knowledges and norms (Guess 2006 as cited in Baffoe et al., 2014), and racism. As a form of legal and cultural property (Harris 2003 as cited in Baffoe et al., 2014), whiteness provides Whites with a package of privileges including higher education, choices of neighborhood, stigmatization of others, and conceptions of beauty and intelligence (Thompson 2004 as cited in Baffoe et al., 
2014). It is plausible that a wide range of social institutions (e.g., legal, economic, political, educational, religious) serve as catalysts to maintain status quo and the hegemony of whiteness and racism as social constructions. Equally important is the negative impact of subtle racism because it causes as much damage as explicit racism does such as selfconfidence issues, poor mental health, diminished social solidarity, and increased social violence among groups (Methven, 2014).

Canada has long asserted its national doctrine of celebrating multiculturalism. Yet, a closer examination of both the social and sporting fabric of the country reveals divergent experiences and tensions not often articulated in dominant discourses. Notwithstanding the original rhetoric to espouse cultural diversity and social inclusion, the current multiculturalism does not do justice towards fully promoting peace, mutual learning, and unification/harmony for all Canadians; instead, it may segregate and reproduce the toxic Eurocentric hegemony leading to inequalities, exclusion, and White supremacy (Guo \& Lloyd, 2015; Gyepi-Garbrah, Walker, \& Gercea, 2014; Henry \& Tator, 2006; Mensah \& Williams, 2015). In other words, the nation-sponsored global images of Canada are projected as being peaceful, beautiful, and clean to the globe, but the reality at the everyday life level appears cosmetic multiculturalism and non-inclusive cultural practices.

\subsection{Visual Politics}

A contemporary global world is full of visual images, symbols, and signs. They are laden with cultural, political, and social meanings and codes, thus changing people's lifestyles, selves, and the public spaces (Barroso, 2014; Gourlay, 2010; Lotman, 2009; Zenenga, 2012). The old cliché proves right even in an era of internet that a picture is worth a thousand words. That is, visuals have become a way of life, and they are as if we cannot live without them; they are like internet or air because they continuously saturate our lives. However, we cannot notice an influence of visuals that permeate our body, mind, and spirit because they are surreptitiously smeared into our life. Images shared on Facebook, Instagram, and Pinterest are a powerful symbolic language in our daily culture, so culture cannot survive without communicating symbols among its members. In this manner, Lotman (1979) argues that as a semiotic mechanism, culture as a collective intellect rather than an individual intellect carries an important apparatus for collective memory and has procedures for creating new messages and meanings. In short, we are bombarded by visual images (Gourlay, 2010), and they transform the social life into a spectacle and illusionary world where they produce simulacra (i.e., an unsatisfactory imitation or substitute) and mask reality (Barroso, 2014).

In contemporary society, most advertising images tend to represent dominant cultural values and meanings (Barroso, 2014; Lefebvre, 1991) because the dominant channels their power in favour of their best interests. Manipulated and controlled by the dominant, visuals are used to unconsciously condition our modes of seeing, speaking, and interpreting, thus preferring certain voices and discourses (Barroso, 2014; Dragan, 2014; Zenenga, 2012). Images may not only circumscribe people's perceptions and actions towards them but also regulate the consumption of services and products. The messages of images have impact on both physical, mental, and social spaces through the 
repetitive practices in everyday life (Bennett, 2014; Lefebvre, 1991). Specifically, dominant images and texts associated with sport and leisure often propagate social inequalities of race, gender, social class, and sexuality through one-dimensional representations for the dominant (Bradbury, 2011; Joseph, Darnell, \& Nakamura, 2012; Zenenga, 2012).Based on literature review, it appears that dominant visual images are ensuring the most likely reproduction of white domination, supremacy, and symbolic violence. Simply put, whiteness is "a concept underlying racism, colonialization and cultural imperialism" (bell, 1990, p. 166), so the mechanism of identity politics is a complex compound of individual, socio-cultural, political, material, and economic phenomena (Mensah \& Williams, 2015). As part of cultural practices, the publication practice (e.g., Mini U) has become a contested and abstract space where power, knowledge, and race are constructed and reproduced by concealing dominant visual images and codes/meanings (Lefebvre, 1991).

Despite the saturating influence of images in everyday life, few studies have focused on the impact of images and social injustices in sport culture. The taken-forgranted images of the dominant are assumed to be normal and standard, but they are problematic because they do not tell us veiled stories that reproduce a skewed status quo in our society. Since television and cinema are an important leisure, "we have become lazy with our eyes" (Silverman, 2004, p. 193). Visuals conditioning our perception thus blind us and prevent us from seeing possibilities and hidden stories behind them (Silverman, 2004). Moreover, little is known about how the Mini U publication practice in academia in general and at the UM in particular, produces certain images and stories. It is especially true that no systematic and critical analysis has been attempted to unveil how the Mini U brochure is represented in a Western Canadian university.

Thus, the purpose of this research was to analyze visual images and texts from the three 2015 and 2016 Mini U brochures that provide young people with sport, recreation, and academic programs.

\section{Methodology}

\subsection{Research Methods}

To analyze the images and texts of the brochures, both semiotics and content analysis were used in this study. Below is the research methodology to address this research problem. Images and texts of the brochures were analyzed qualitatively first and then quantitatively. In this respect, this study is similar to a qualitative content analysis, which assigns categories and meanings to texts by reading and interpreting the contents and contexts. The quantitative step analyzed the quantities of categories and meanings (Mayring, 2014).

Semiotics is the study of meaning and theory of signs offering methods to question the meaning of social practices and cultural productions of humans (Silverman, 2004). It is the research of signs, including both the signifier (e.g., a picture or appearance) and the signified (e.g., the picture's hidden meaning/concept or reality) (Silverman, 2004). Contemporary semiotics focuses on a dynamic concept of semiosphere that includes all dimensions of cultural semiotics and serves as a functional mechanism to know diachronic and synchronic processes of signs (Lotman, 2009). This 
semiotics space, semiosphere, is interconnected with individual, communal, and cultural relationships in countless ways so that a wide range of possibilities between semantic elements creates multiple and complex meanings (Lotman, 2009). From this cultural point of view, semiotics deals with cultural systems that influence the construction of social reality. Another important emerging trend in semiotics is the emphasis on an ethical and political position of semioticians collaborating with other social and humanistic scientists. They are interested in power differentials and hegemonic and counter-hegemonic practices for marginalized groups (Bennett, 2014; Lotman, 2009; Zenenga, 2012). Semioticians with a radical ethics pursue a deconstructive and transformative semiotics to reveal deeply embedded cultural meanings and codes (Zenenga, 2012) and identify collective lies from signs.

The use of a qualitative visual methodology has been lacking from previous analyses of publication visuals because of the positivistic influence on the analysis of texts and visuals (Lynn \& Lea, 2005). In spite of an aesthetic perspective of visual imagery and the antithesis of science, namely, non-positivism (Lynn \& Lea, 2005), analyzing visuals and texts is still important to see social processes because shared images and texts are social constructions of 'make-believable-realities' enacted by the dominant. For the visual data, social theories play an important role in identifying the critical assumptions in our life and making meaningful interpretation and action by analyzing visuals (Silverman, 2004). During the analysis of textual and visual works, we should not lose sight of how these works tell dominant stories (Silverman, 2004). Equally important is the power of resistance to the dominant stories as the oppressed make their own narratives through their oral stories, images, and texts and interpretations.

Content analysis is a systematic and standard method to analyze contents in empirical social research (Mayring, 2014). Content analysis can be used for analyzing the brochures because it focuses on counting images and interpreting themes of the brochures in both quantitative and qualitative ways. In this regard, qualitative analysis of visuals complements quantitative data analysis to better understand the social construction of social/racial exclusion viewed from a social justice/transformative framework. The forms of content analysis can be any recorded communication artifacts as either primary or secondary content, and contents in question are analyzed according to the predetermined objective criteria (e.g., clarity, colour, size, number, gender, race, allocation of figure), thus making different coders reach the same results (Kirby, Greaves, \& Reid, 2006).

\subsection{Data Analysis}

Table 1 shows the research procedures of semiotics and content analysis. At first glance, those procedures look like sequential steps, but they unfold more like a spiral or cycle (Creswell, 2013). Having said that, researchers can go back and forth and may return to any research stage dependent on what information, data analysis, interpretation, and presentation are needed. In this study, the procedures of data analysis are recursive with the elements of description, analysis, and interpretation based on Wolcott's concept (1994). Further, three analytical frameworks in which data are analyzed will be implemented: (1) a clear analytical perspective (e.g., sign analysis); (2) the application of 
relevant theory (i.e., racial theory); and (3) a detailed data analysis. Specifically, qualitative data analyzed visual images and texts looking for specific references to a quality of pictures (e.g., clarity, size, race, allocation of pictures such as centre or peripheral), "diversity", "whiteness", "racism”, "multiculturalism”, or similar concepts. Quantitative data analysis counted the number of young people and leaders (i.e., Mini U leaders who are UM students and lead Mini U programs) in pictures of the brochures who seemed to be members of the White dominant majority and then counted the number of young people and adults depicted who appeared to be members of non-White visible minority groups. Also, the number of the offered sport and leisure programs in the brochures was analyzed based on the White-centric or ethnic-oriented sport and recreation programs.

Table 1. Visual Research Procedures

\begin{tabular}{ll}
\hline Step & Description \\
\hline 1. Sampling & a. Formulation of research problem. \\
& b. Purposeful sampling to find maximum images and numbers. \\
2. Data management & c. Multiple researchers to minimize researcher bias. \\
& a. Organizing and immersing in data. \\
& b. Reading data and doing margin notes. \\
3. Semiotic analysis & a. Interpretation of visuals across visual modes. \\
& b. Denotative visuals = analogical to reality and interpreted \\
& literally. \\
& c. Connotative visuals = supplementary to reality \& interpreted \\
& theoretically in cultural contexts. \\
4. Content analysis & a. Establishment of category systems of visuals and texts. \\
& b. Determination of analysis units (recording, context, and \\
classification). & c. Coding of dominant images denotatively and connotatively. \\
d. Arranging and quantifying representative visuals into themes. \\
a. Interpreting results through analytic memos and social justice \\
framework. \\
b. Searching for alternative understandings. \\
c. Representing, writing, and visualizing data.
\end{tabular}

Adapted from: Creswell 2013; Hunter 2013; Marshall and Rossman 2011.

\subsection{Study Sample}

The 2015 spring and summer (brochure 1), 2015-2016 fall and winter (brochure 2), and 2016 spring and summer (brochure 3) editions of the three brochures at the University of Manitoba were chosen as a study sample. The three brochures that have been published in consecutive seasons and years were used to make general patterns of the three brochures. Annually, more than 6,000-7,000 young people between 4 and 16 years old participate in Mini $\mathrm{U}$ that is entering the 38th year since its inception. As a year-round program offering spring, summer, fall, and programs, the summer Mini $U$ is the largest summer day camp in North America offering 58 different programs ranging from sport, recreation, art, science, engineering, to leadership. Mini $\mathrm{U}$ is advertised through both online, posters, and hard copy marketing tools throughout campus, Winnipeg, and its surrounding communities. It should be cautioned that there might be potential gender, disability, and social class themes arising from the brochures, but 
the scope of this research is limited to race and racism. Thus, this research seeks to find racial/social exclusion and whiteness issues to better understand them and to call for social change and a racial-friendly publication practice of the brochures.

\section{Results}

\subsection{Qualitative Results}

The themes of race, social exclusion, and whiteness were revealed after examining the brochures. When the lead researcher first scanned the brochures, the overall impression of the visual images for the three brochures appeared a predominant reflection of whiteness. It is clear to the researchers that after thoroughly examining the brochures, the dominant imagery of the brochures is that of White children, youth, and Mini U leaders (read UM students). ${ }^{1}$ The same phenomenon is apparent in the online space of the Mini $U$ website that is also dominated by the pictures of White children and youth.

Suffice it to say, the visual images of White children and youth dominate the portraits of the brochures regardless of their picture sizes. For example, a cover page picture of the brochure 1 depicted a White child with light-coloured curly hair smiling on using the climbing wall at the UM Active Living Centre gym. This image occupied an entire cover page equivalent to a letter size. Specifically, a facial dimension of the cover page picture for the White child was $9 \times 9$ centimeters, which is twice as big as the smallest picture size, $4 \times 4$ centimeters. Further, the table of contents and the welcome message on pages 2 and 3, the second most important information of the brochure 1 following the cover page, depicts another picture of White children. It fills up threequarters of the entire two pages with five White children smiling at the swimming pool edge. Their facial dimensions measured $6 \times 9$ centimeters, thus making those children highly visible. Moreover, all the nine introductory pictures of each program (e.g., experience, sport program) whose dimensions are half a letter size emphasize White only pictures. Those images are clear enough to identify them as young White people using the front body-view picture technique and mixing with another supplementary small picture just below big pictures (e.g., experience on page 4 and ice programs on page 38). Exceptions are the aquatics program picture on page 9 that includes an image of both a White child and a non-White one showing only their backs and the recreation program picture on page 27 with three White children and one Asian child.

Only one whole picture on page 28 among 59 pictures highlighted a child of color, but its picture size was only $9.5 \times 4.5$ centimeters. The picture showed a Black child's upper back body and his face when he was on his stomach in the playground getting out of an inflated bouncy castle, and the picture dimension of the child's face was only 2 × 2 centimeters. In addition, almost all pictures showing non-White figures were either peripheral, mixed group pictures with young White people, small background ones, or partial view pictures exposing side and limited parts of the bodies of non-White

${ }^{1}$ Authors cannot include any pictures of the Mini U brochure in this manuscript because the Mini $\mathrm{U}$ director is not able to provide permission for the pictures to be used for research purpose. Please see the website for the Mini $U$ website for more information at:

https://issuu.com/umanitoba/docs/2016_mini_u_programs_spring__summe 
people, so they were not easy to identify. Further, if researchers look closely at the Mini U leaders' pictures who are usually the UM students, the brochure 1 clearly tells a onedimensional story of whiteness to a greater degree than the children and youth pictures represented. In fact, there were no pictures of leaders of color in the brochure 1 as all leaders shown on the pictures construct a narrative of White images but ignore nonWhite people. However, there are leaders whose culture and heritage are diverse among Mini U leaders, but no leaders of color exist in the tale of the brochure 1. Moreover, it appears that there are no staff members of colour on the Mini $U$ website. However, there are five pictures of White staff and the other two staff whose last names appear to be of European origins (e.g., Rowson and Prokesch), so all Mini U staff shown online appear $100 \%$ White.

One notable exception was the picture with Indigenous figures (e.g., the picture size is half a page) on page 8 that showed two Indigenous youths and one adult, and the adult appears to look White at first glance. Although Indigenous populations are continuously growing (e.g., almost one of out five is Indigenous in Winnipeg) (Macdonald, 2015), the brochure 1 depicted only two young Indigenous people; this year in 2016 will be the third Mini U specifically for Indigenous young people even though Mini $U$ has entered its 38th year of history at the UM. Indigenous children and youth have been marginalized by the main stream sport and leisure culture of whiteness as they may not have had culturally relevant programs to participate in sport and recreation including Mini $\mathrm{U}$ in part due to racism, poverty, Indian residential school history, and a general lack of support and cultural sensitivity and safety (Halas, McRae, \& Carpenter, 2013; Halas, McRae, \& Patherick, 2012; Lavallee \& Levesque, 2013).

The offered programs of Mini U tend to be oriented for young White-centred patterns. The provisions of Mini $U$ seem to be more likely focused on certain White friendly programs rather than the general population ones. For instance, spring break programs on pages 14-16 provided young people with six different programs, but three of which were wall climbing, hockey, and skate programs that are generally considered to be White dominant sports (Fletcher, 2008; MacDonald, 2011). However, the sessions of soccer and basketball conceived as ethnically dominant sports by the public and media (Mauro, 2013; Ricatti \& Klugman, 2013) were included all together under the sport sampler program category, and its program description was only one paragraph. Moreover, there was half a letter-size picture of wall climbing along with a small one in the introductory page: one for dodgeball, one for hockey, and one for gymnastics; each of the wall climbing, hockey, and skate programs had a paragraph of its program description (e.g., three paragraphs in total) that means more information spaces for those programs. However, soccer (Mauro, 2013; Ricatti \& Klugman, 2013) or basketball that is considered as ethnic sports had only one paragraph for its program description in the brochure 1. All in all, Mini U programs seemly are designed for young White people with respect to types of programs and marketing tactics of the programs.

The same skewed cultural publication practice applied to the off-campus recreation program on pages 30-31 of the brochure 1. It houses canoeing, kayaking, xtreme adventures, wall climbing, fencing, and golf considered to be White dominant activities (Fletcher, 2008; MacDonald, 2011); however, in the brochure 1, none of the information or program was given to table tennis, wendo, yoga, meditation, K-pop, tai 
chi, hip hop dancing, taekwondo, or badminton that are generally considered to be multicultural, ethnic and non-extreme adventures or relaxed leisure (Walker \& Wang, 2008). In stark contrast, as a major separate section, ice programs including hockey, skate, and ringette occupied four pages and provided nine domain-specific programs, and their program descriptions were richly detailed with the description lengths of 11 different programs ranging between six lines and 11 lines per paragraph. To the contrary, volleyball had only two sessions and soccer three sessions within just one page, and their lengths of the program descriptions ranged between only four and eight lines on pages $36-37$.

Regardless of any kind of programs, the analysis of images and texts of the brochure 1 indicates that Mini $\mathrm{U}$ and its marketing strategies (read the Mini brochure) tend to reproduce the dominant White images of young people. Most importantly, the very similar patterns and publication practices of racial exclusion and whiteness that are revealed in the 2015 spring and summer brochure are also found in both 2015-2016 fall and winter and 2016 spring and summer brochures too.

\subsection{Quantitative Results}

To better analyze the brochures, qualitative analysis of semiotics can be strengthened by mixing with quantitative content analysis. Table 2.1. shows the number of picture sizes in relation to White and non-White young people and leaders of the brochure 1. All large pictures of letter size (i.e., $28 \times 21.5$ centimeters) and 1.5 letter size (i.e., $40 \times 21.5$ centimeters) focused on White young people, but there were no large pictures (e.g., letter size and 1.5 letter size) for non-White young counterparts at all. In other words, $100 \%$ of all the large pictures depicted White children in the brochure 1 . Among 16 half letter-size pictures, only one half letter size picture seemed to represent non-White youth. Consequently, the ratio of White and non-White figures for the halfsize picture was $93 \%$ for the former and $7 \%$ for the latter. There were nine quarter letter-size pictures (i.e., 13 x 7-10 centimeter), but none of them depicted an ethnic-only picture. Thus, the ratio between White and non-White for the quarter size picture was $100 \%$ for White and $0 \%$ for non-White young people. 28 pictures in total were found in the small size picture, but there was only one picture depicting non-White child in this category. Thus, the racial ratio of the category of this picture size made a great difference of $96 \%$ for White and only $4 \%$ for non-White young people. In addition, the number of small size pictures (i.e., 4 x 4 centimeters) for mixed young people appeared to stand out due to its total number of six pictures compared with 21 for White children. Finally, the overall racial ratio of the total picture sizes was $95 \%$ for White young people (e.g., 40 pictures) and $5 \%$ for non-White young people (e.g., 2 pictures). 
Table 2.1. Picture Sizes and Racial Categories of Young People and Leaders, 2015 Spring and Summer

\begin{tabular}{lllllll}
\hline & $\begin{array}{l}\text { Young } \\
\text { White } \\
\text { people }\end{array}$ & $\begin{array}{l}\text { Young } \\
\text { non-White } \\
\text { people }\end{array}$ & $\begin{array}{l}\text { Mixed } \\
\text { White } \\
\text { non-White }\end{array}$ & $\begin{array}{l}\text { White } \\
\text { leader }\end{array}$ & $\begin{array}{l}\text { Non-White } \\
\text { leader }\end{array}$ & Total \\
\hline 1.5 Letter size & 1 & 0 & 0 & 0 & 0 & 1 \\
Letter size & 1 & 0 & 0 & 0 & 0 & 1 \\
Half size & 9 & 1 & 2 & 4 & 0 & 16 \\
Quarter size & 8 & 0 & 1 & 0 & 0 & 9 \\
Small size & 21 & 1 & 6 & 4 & 0 & 32 \\
Total & 40 & 2 & 9 & 8 & 0 & 59 \\
\hline
\end{tabular}

Note. 29 unidentified pictures due to the quality of pictures are not included in this analysis.

Table 2.2. highlights the total number of White and non-White young people and leaders. There were at least 136 White figures in the brochure 1 while there were only 15 identifiable non-White ones examined through mainly skin and facial colour of pictures. None of the Mini U leaders was non-White, but 14 leaders were White. More specifically, $89 \%$ of figures of children and youth were White, but only $11 \%$ accounted for non-White racial groups irrespective of their age. Moreover, 100\% of all Mini U leaders were White but $0 \%$ of non-White leaders in the brochure 1 . In some sections, there were no non-White pictures, and the examples of them were found in off-campus recreation, sport-specific, and ice programs from pages 30 to 41 . All 15 pictures among those program sections were of exclusively White young people and leaders but no nonWhite counterparts.

Table 2.2. Total Number of White and Non-White Young People and Leaders, 2015 Spring and Summer

\begin{tabular}{lllll}
\hline & All White & All Non-White & White Leader & $\begin{array}{l}\text { Non-White } \\
\text { Leader }\end{array}$ \\
\hline \# of Figure & 136 & 15 & 14 & 0 \\
$\%$ of Figure & $89 \%$ & $11 \%$ & $100 \%$ & $0 \%$ \\
\hline
\end{tabular}

Note. 29 unidentified pictures due to the quality of pictures are not included in this analysis.

Table 2. 3. shows the frequencies of sport and recreational programs and the total numbers of their sessions. Overall, the most dominant sport and recreation program was the ice programs, the hockey-oriented program, as there were at least nine major hockey-related programs (e.g., goalie in net) including one ringette program and 28 sessions depending on age groups. The 28 sessions for ice programs were three times higher than the second highest session of either soccer, basketball, or wall climbing, having nine sessions, respectively. If the flag football and field hockey combo that includes a form of hockey were added to the ice programs, the total sessions of ice programs would reach up to 30 . The total 28 sessions of ice programs far exceeded the number of a combination of soccer, volleyball, and basketball, 25 as a team sport category. To reiterate, ice programs (28 sessions) alone accounted for almost $67 \%$ compared with soccer (nine sessions) or basketball (nine sessions) and $82 \%$ compared with volleyball (5 sessions) whose categories are team sports. Equally remarkable were 
the total nine sessions of wall climbing and five sessions of outdoor exploration compared with only one session of judo or karate. Likewise, both xtreme adventures with three sessions and outdoor exploration had wall climbing repertoires, so the possible number of wall climbing regardless of its programs would be higher than the real number of wall climbing per se illustrates.

Table 2.3. Sport and Recreation Programs and Number of Sessions, 2015 Spring and Summer

\begin{tabular}{|c|c|c|c|c|c|}
\hline $\begin{array}{l}\text { Sport/Rec } \\
\text { Program }\end{array}$ & \# Programs & \# Sessions & $\begin{array}{l}\text { Sport/Rec } \\
\text { Program }\end{array}$ & $\begin{array}{l}\text { \# } \\
\text { Programs }\end{array}$ & \# Sessions \\
\hline Indigenous Mini U & 1 & 1 & Wall Climbing & 1 & 9 \\
\hline Judo & 1 & 1 & Soccer & 3 & 9 \\
\hline Karate & 1 & 1 & Volleyball & 2 & 5 \\
\hline Cheerleading & 1 & 3 & Basketball & 4 & 9 \\
\hline Tennis & 1 & 3 & $\begin{array}{l}\text { Flag Football/Field } \\
\text { Hockey Combo }\end{array}$ & 1 & 2 \\
\hline $\begin{array}{l}\text { Archery, Fencing, \& } \\
\text { Racquetball }\end{array}$ & 1 & 3 & $\begin{array}{l}\text { Outdoor } \\
\text { Exploration }\end{array}$ & 1 & 5 \\
\hline Xtreme Adventures & 1 & 3 & Ice Programs & 9 & 28 \\
\hline
\end{tabular}

Note. Ice programs include hockey, skate, goalie training, and shooting and scoring in hockey.

Images of White people are the most prominent images of the UM, and an overwhelming number of images for White people in the brochure 1 appear to be prominent. All in all, the general visual images of the brochure 1 illustrates an overarching visual narrative of whiteness at the UM. Likewise, both brochure 2 and brochure 3 are conformed to the general patterns of racial exclusion and whiteness of the brochure 1.

Tables 3.1., 3.2., and 3.3. show the results of the brochure 2.

Table 3.1. Picture Sizes and Racial Categories of Young People and Leaders, 2015-2016 Fall and Winter

\begin{tabular}{lllllll}
\hline & $\begin{array}{l}\text { Young } \\
\text { White } \\
\text { people }\end{array}$ & $\begin{array}{l}\text { Young } \\
\text { non-White } \\
\text { people }\end{array}$ & $\begin{array}{l}\text { Mixed } \\
\text { White } \\
\text { non-White }\end{array}$ & $\begin{array}{l}\text { White } \\
\text { leader }\end{array}$ & $\begin{array}{l}\text { Non-White } \\
\text { leader }\end{array}$ & Total \\
\hline $\begin{array}{l}\text { Half size } \\
\text { Quarter }\end{array}$ & 0 & 0 & 1 & 0 & 0 & 1 \\
$\begin{array}{l}\text { size } \\
\text { Small size }\end{array}$ & 5 & 0 & 2 & 2 & 0 & 7 \\
Total & 5 & 0 & 1 & 3 & 1 & 10 \\
\hline
\end{tabular}

Note 1. 4 unidentified pictures due to the quality of pictures are not included in this analysis.

Note 2. The full dimension/size of 2015-2016 fall and winter Mini U brochure is half size. 
Table 3.2. Total Number of White and Non-White Young People and Leaders 2015-2016 Fall and Winter All White All Non-White White Leader Non-White Leader

\# of Figure

56

$87 \%$

8

$13 \%$

$87 \%$

$13 \%$

Note. 4 unidentified pictures due to the quality of pictures are not included in this analysis.

Table 3.3. Sport and Recreation Programs and Number of Sessions, 2015-2016 Fall and Winter

\begin{tabular}{|c|c|c|c|c|c|}
\hline $\begin{array}{l}\text { Sport/Rec } \\
\text { Program } \\
\end{array}$ & \# Programs & \# Sessions & $\begin{array}{l}\text { Sport/Rec } \\
\text { Program }\end{array}$ & $\begin{array}{l}\# \\
\text { Programs }\end{array}$ & \# Sessions \\
\hline $\begin{array}{ll}\begin{array}{l}\text { Hockey } \\
\text { camp }\end{array} & \text { Shots } \\
\end{array}$ & 1 & 1 & Super Soccer & 1 & 1 \\
\hline Goalie & 1 & 1 & Racquetballers 1 & 1 & 2 \\
\hline Checking camp & 1 & 1 & Racquetballers 2 & 1 & 2 \\
\hline Power Skating & 1 & 1 & Tennis & 1 & 1 \\
\hline Learn to Skate 1 & 1 & 2 & Run Club & 1 & 1 \\
\hline Learn to Skate 2 & 1 & 4 & $\begin{array}{l}\text { Junior } \\
\text { Track/Field }\end{array}$ & 1 & 1 \\
\hline Learn to Skate 3 & 1 & 2 & Sport Sampler & 1 & 1 \\
\hline
\end{tabular}

The results of the brochure 3 are displayed at Table 4.1., 4.2., and 4.3 in the next sections.

Table 4.1. Picture Sizes and Racial Categories of Young People and Leaders, 2016 Spring and Summer

\begin{tabular}{lllllll}
\hline & $\begin{array}{l}\text { Young } \\
\text { White } \\
\text { people }\end{array}$ & $\begin{array}{l}\text { Young } \\
\text { non-White } \\
\text { people }\end{array}$ & $\begin{array}{l}\text { Mixed } \\
\text { White } \\
\text { non-White }\end{array}$ & $\begin{array}{l}\text { White } \\
\text { leader }\end{array}$ & $\begin{array}{l}\text { Non-White } \\
\text { leader }\end{array}$ & Total \\
\hline $\begin{array}{l}1.5 \\
\text { size }\end{array}$ & 0 & 0 & 1 & 0 & 0 & 1 \\
Letter size & 2 & 0 & 0 & 0 & 0 & 2 \\
$\begin{array}{l}\text { Half size } \\
\text { Quarter }\end{array}$ & 6 & 0 & 3 & 4 & 0 & 13 \\
size & 13 & 0 & 3 & 3 & 0 & 19 \\
Small size & 7 & 0 & 1 & 5 & 1 & 14 \\
Total & 28 & 0 & 8 & 12 & 1 & 49 \\
\hline
\end{tabular}

Note. 40 unidentified pictures due to the quality of pictures are not included in this analysis.

Table 4.2. Total Number of White and Non-White Young People and Leaders, 2016 Spring and Summer

\begin{tabular}{lllll}
\hline & All White & All Non-White & White Leader & $\begin{array}{l}\text { Non-White } \\
\text { Leader }\end{array}$ \\
\hline \# of Figure & 113 & 16 & 17 & 1 \\
$\%$ of Figure & $88 \%$ & $12 \%$ & $94 \%$ & $6 \%$ \\
\hline
\end{tabular}

Note. 40 unidentified pictures due to the quality of pictures are not included in this analysis. 
Table 4.3. Sport and Recreation Programs and Number of Sessions, 2016 Spring and Summer

\begin{tabular}{|c|c|c|c|c|c|}
\hline $\begin{array}{l}\text { Sport/Rec } \\
\text { Program }\end{array}$ & \# Programs & \# Sessions & $\begin{array}{l}\text { Sport/Rec } \\
\text { Program }\end{array}$ & $\begin{array}{l}\text { \# } \\
\text { Programs }\end{array}$ & \# Sessions \\
\hline Indigenous Mini U & 0 & 0 & Wall Climbing & 2 & 12 \\
\hline Judo & 1 & 1 & Soccer & 3 & 10 \\
\hline Karate & 1 & 1 & Volleyball & 2 & 5 \\
\hline Cheerleading & 2 & 4 & Basketball & 3 & 7 \\
\hline Tennis & 2 & 3 & $\begin{array}{l}\text { Flag Football/Field } \\
\text { Hockey Combo }\end{array}$ & 1 & 1 \\
\hline $\begin{array}{l}\text { Archery, Fencing, } \\
\text { \& Racquetball }\end{array}$ & 2 & 3 & $\begin{array}{l}\text { Outdoor } \\
\text { Exploration }\end{array}$ & 2 & 7 \\
\hline Xtreme Adventures & 1 & 3 & Ice Programs & 7 & 26 \\
\hline
\end{tabular}

Note. Ice programs include hockey, skate, goalie training, and shooting and scoring in hockey.

\section{Discussion}

Above all, this study demystifies how the Mini $U$ publication has normalized the predominance White images on campus. This study also shows that the biased publication practice employed by the leadership at the UM does not work toward building a culture of inclusion that reflects the diversity and pluralism of Canadian society. The results of this study are contradictory to the current streams of the UM president's strategic priorities (University of Manitoba, 2014) and the national policy of multiculturalism in Canada (Guo \& Lloyd, 2015). One of the president's priorities is to build community that creates an outstanding learning and working environment, and including racial minorities is one of the goals under that banner (University of Manitoba, 2014). To make matters worse, the strategic plan for 2015-2020 at the UM does not include addressing any racism-related issues at all in that there are no mentions of policies specifically addressing racism in the entirety of the 26 pages. The same phenomenon applies to the Mini U publication culture at the UM. As a matter of fact, there is no information, policy, or protocol (e.g., zero tolerance policy of racism or discrimination) on how to deal with and educate about issues related to racial discrimination, teasing, bullying, or violence in the brochures 1, 2, and 3. On page 18 of the brochure 1, it only mentions that children who are deemed to have "misbehaved" will be asked to leave a program, and their parents will be contacted without a refund.

The racial discrepancies reflected in the images of the brochures are align with the current literature of racialized academy in Canada. For instance, 96\% of faculty and staff in physical education and kinesiology at higher educational institutions across Canada were Whites while racialized minorities, and Aboriginal females were poorly underrepresented (Douglas \& Halas, 2013). Literature supports this idea that the Faculty of Kinesiology and Recreation Management (FKRM) and other disciplines in humanities and social sciences have a higher number of White staff and faculties (Douglas \& Halas, 2013) than the other faculties in engineering and sciences (Eisenkraft, 2010).

Beyond social exclusion embedded in post-secondary educational institutions, it is important to connect campus racism to the larger society in Canada to fully understand the socio-political mechanism of racism and social justice. The Mini U brochures cannot be isolated from both the UM and the Canadian society that determine 
their philosophy and contents, so they cannot be analyzed without taking into account the macro issues either. Clearly, all brochures express the president's strategic directions for the UM, but the Government of Canada's federal policy, multiculturalism, has not been addressed at all in the brochures. The implication is that the ideological and governmental levels of policies are different from front-line practices, thus resulting in huge distances between the national policies and everyday life practices on campus (read the brochures). It appears that both the UM leadership and the Canadian government project the positive images of their constitutions using desirable languages and images like 'multiculturalism' and 'trailblazers'. However, in reality, the issues of racism and racial exclusion are not substantively dealt with in both the organizations although there are a plethora of advertised signs that act as visual pollutions with which to prevent the public from seeing the true reality by concealing and distorting certain images and texts (Barroso, 2014).

Even the mission statement of the brochure 1 on page 47 reads that Mini $U$ strives to: (1) develop educational leaders in children/youth physical activity and (2) provide excellent and inclusive recreation/sport and educational experiences to young people. In stark contrast, the brochures appear to highlight the opposite directions of the Mini U mission statement and the Government of Canada as far as visual images full of White figures are concerned. Likewise, hockey, a White dominant sport, is overemphasized, but the most practiced growing sport, soccer, among Canadian children and youth aged from 5 to 14 gets much less resource endowment in Mini U. Specifically, $42 \%$ of young people play soccer over hockey $(22 \%)$, and soccer has been the most played and popular sport among young people in Canada since 1998 (Shendruk, 2014). For this reason, the Government of Canada may produce a false sense of multiculturalism, or they unconsciously and collectively deny the 'blasphemy' of racism in Canadian society.

These kinds of hidden practices make potential participants who may be interested in Mini $\mathrm{U}$ mistakenly believe that White culture tend to dominate sport and recreation on campus and in Canadian society. Most importantly, non-White groups may rethink or be hesitant to send their offspring to White-oriented Mini $U$ programs because of a possible racism and discrimination they may encounter. Marginalized parents do not want their children to experience social ills in sport and recreation because they know them through their lived experiences. For instance, immigrants are most likely to engage in swimming $(35 \%)$, soccer $(23 \%)$, or badminton $(15 \%)$ rather than hockey $(2 \%)$, football $(3 \%)$, or rugby $(1 \%)$ due to previous familiar cultural practices and ease to access with the former as well as racial discrimination with the latter (Institute for Canadian Citizenship, 2014). Moreover, higher positions such as Mini U leaders are dominantly White, so they tend to naturalize White supremacy over people of color through visual images in the brochures. Naturally, it legitimizes the assumption that higher positions at any level are filled up by White people in Canadian society; as for Mini U, although there are many non-White Mini U leaders equally capable of doing the same job as their White counterparts, they are not shown in the pictures.

As the biggest major university that creates (misleading) knowledge, the UM is a role model within Winnipeg and Manitoban communities. The UM also serves as a place where social knowledge and practices such as racism are learned, disguised, or 
disseminated (e.g., the brochures). In fact, education and educational institutions were first used as a powerful weapon to construct the colonial ideologies and whiteness by oppressing voices of those colonized (Cote 2009), and it still continues to exist at education contexts regardless of levels of education physically and culturally. In spite of anti-racism and de-colonialization movements, they may reinforce or propagate racism and re-colonialization. The reason is that those movements may stay at an ideological and theoretical level (i.e., government policies) without influencing the everyday practice of invisible racism on campus such as the 'adulterated' Mini U publication production. To reiterate, it does not mean that anti-racism movements do not work, but that they have a long way to go to make our campus relatively free of racism because of the subtle and covert racism in Western society and in higher educational institutions (Clark et al., 2014; Harwood et al., 2015; Satzewich, 2010; Smith, 2015; Tator \& Henry, 2010).

Kincheloe and McLaren (2008) also articulate how symbolic and cultural violence such as racism complements the direct and structural violences of the ruling class, therein reproducing social inequalities for the marginalized. As seen earlier, meaning-making is not only ascribed to pictures per se but also to the hidden assumptions of social processes of social exclusion engrained in the special designs, privileged organizations, images, and contents/texts for White people in the brochures. By granting bigger pictures, higher frequencies, and more spaces of images for White people and White-oriented programs such as hockey or climbing, the brochures per se tend to reproduce whiteness and racial exclusion.

From a critical point of view, multiculturalism has ghettoized ethnic communities and segregated racial groups in Canada due to its focus on the coexistence of ethnic enclaves (e.g., side by side) instead of intercultural learning, cooperation, and dialogue (Guo \& Lloyd, 2015; Gyepi-Garbrah et al., 2014; Henry \& Tator, 2006). Even though Canada champions multiculturalism as a sovereign dogma, racism and discrimination pervade in everyday Canadian life (Douglas \& Halas, 2013; Freund, 2015; Guo, 2015; Halas et al., 2012; 2103; Henry \& Tator, 2006; Zaami, 2015). In spite of the widespread multiculturalism, Canada has not fully removed socio-structural-cultural barriers deeply entrenched in our society, such as racism and whiteness, thereby making marginalized populations to feel a lost sense of belonging to Canada (Mensah \& Williams, 2015; Veronis, 2015). This argument explains why racialized groups need to find their own 'ethnic' spaces or cultural heaven as forms of resistance and survival mechanism such as ethnic churches or cultural centers, so they feel a sense of belonging and free from racism. In a cultural space, the marginalized groups feel comfortable and secure as if in a motherland as they are temporarily escaped from life stressors in a host society.

Marginalized groups are vulnerable to social exclusion during sport participation (Bradbury, 2011; Hay, 2011; Hylton, 2009; Joseph et al., 2012; Mauro, 2013) and even before their engagement in sport and leisure via the racialized Mini $U$ publication as shown in this research. Citing Marx's dialectical materialism, Andrews and Giardina (2008) argue that people make their own working, leisure, political, religious, and sport lives not their own choices but under certain conditions in a particular social location. That is why there are so many 'ethnic' sport and recreation teams because racialized minorities have often been marginalized and excluded from the mainstream ones (Hay, 
2011; Mauro, 2013); they gain a sense of belonging/security and ethnic pride and loyalty from their ethnic teams where they can resist power imbalance and negotiate spoiled identities (Bradbury, 2011; Mauro, 2013; Ricatti \& Klugman, 2013; Rich, Misener, \& Dubeau, 2015; Ugolotti, 2015). However, considering the social production of racism, we should keep in mind that "It was not black people who should be examined, but white society; it was not a case of educating blacks and whites for integration, but of fighting institutional racism; it was not race relations that was the field for study, but racism" (Bourne 1981, p. 339, as cited in Oliver, 1992, p. 112).

\section{Conclusion}

An attentive reading of the brochures 1, 2, and 3 of 2015 and 2016 at the UM, Canada deconstructs how racialized publication practices reaffirm whiteness at the expense of non-whiteness and sell colonial legacies of marginalization in a post-colonial era. Marketing materials serve as a critical medium to communicate, construct, and reproduce white privileges, power, and racial exclusion. Any practice at post-secondary institutions are not immune and not dissimilar to the other spheres of social institutions where social exclusion is maintained by advertising signs that hide dominant cultural values.

In principle, any critique of social relations needs applied and radical ethics (Cannella \& Lincoln, 2013). Suvorov and Suvorova (2016) remind us that "The precept "Do not harm!" is the origin and foundation of proper ethical principles of human behaviour" (p. 385). We need to consider power changeable and discursive and to deconstruct domination, privilege, vertical democracy, and oppression by connecting them to transformative ethics (Cannella \& Lincoln, 2013). Paraphrasing Lefebvre's utopian moment, what is the impossible-possible of action for social change? We need to call for social actions based on an analysis of the brochures. The following is recommendations to combat campus racism and social inequalities.

First, culturally and socially inclusive marketing strategies are necessary for the UM, FKRM, and Mini U office. Socially integrative Mini U publications and programs (e.g., more pictures of non-White, soccer sessions, K-pop) can produce more balanced advertising brochures in contrast to the racialized brochures. For example, in the production of a culturally friendly brochure, it is critical to include balanced information and to represent visuals of diverse races and ethnicities. Better brochures may entice more diverse young customers into Mini $\mathrm{U}$ in the long term. Ultimately, participation in inclusive sport and recreation can help marginalized young people to effectively integrate into the dominant society and cultivate their cultural identity and development (Rich, Misener, \& Dubeau, 2015; Ugolotti, 2015). Images in the brochures tend to reproduce the hegemony of the dominant culture. Racism comes from channelled information such as unidimensional Mini $\mathrm{U}$ images and texts and the lack of education about the false history of both the dominant and racial groups resulting in a fear of different races and their cultures. Suffice it to say, deconstructive semiotics principles (Zenenga, 2012) apply to all campus advertising to better represent the truly diverse faces and stories of the UM. Education about the importance of pluralism, diversity, and equity for campus members is the key to create socially inclusive marketing products. 
Second, to combat campus racism, it is necessary to educate campus members about white privilege, racism, social justice, and democratic multiculturalism. To do so, an important first step is to offer education and training on the social inclusion and social change for campus members. For example, incorporating an educational module on diversity, racial relations, and equity into the curriculum and new employee training is one way to educate campus communities. However, this kind of education should be systematic and consistent over a long time at any institution in order to change the status quo of social exclusion. Furthermore, the slogan "Kick off Racism" at Mini U could be a small meaningful gesture in an attempt to achieve a collective campus movement and to understand and decrease racism by targeting young people and adults at a grassroots level. This kind of movement is especially important in Winnipeg, Manitoba where almost one of fifth of the population is Indigenous people. Thus, a growing number of Indigenous children and youth in Manitoba and at the UM require our collective actions to ensure that the UM is equipped with a welcoming and culturally relevant context for young Indigenous people. Supported by the UM leadership, offering systematic and sustainable commitment to racism and equity programs enables the entire campus to be aware of social justice issues beyond the new student and employee training programs.

Third, creating a higher senior position of diversity, equity, and racism under the presidential office shows the entire campus a strong initiative to eliminate racism and social exclusion. There is no position and information dealing with racism in the UM Strategic Plan 2015-2020. For instance, a vice-president of diversity and inclusion is a good initiative to address social injustices on campus, so she/he can manage and guide the position's mandates to all campus units. Instead of relying on the human resource department to some extent in dealing with race and diversity issues, the senior manager can set up specific and measurable standards against which they monitor hiring, retention, and promotion processes with respect to balanced racial ratios (e.g., $20 \%$ new employees for racialized groups). If there is any violation of such policy in any unit, then the vice-president of diversity and inclusion has the authority to investigate and intervene. As mentioned before, $96 \%$ of faculty and staff in physical education and kinesiology across Canada are White (Douglas \& Halas, 2013). Thus, creating a higher senior position for diversity, inclusion, and racism may facilitate diverse workforce compositions of staff, faculty, and students and an inclusive campus environment.

Finally, the Canadian government should make collective efforts to accomplish democratic multiculturalism so that policies and programs can be made towards eliminating entrenched colonial ills such as racism, white domination, and power imbalance. Instead of being propagated in the federal government level through ideological signs and images, an application of democratic multiculturalism practiced in everyday life is crucial to change social injustices. Particularly vulnerable are racialized groups because in many cases they do not have the power and resources to manage structural life challenges along with their marginalized identity. Those who are marginalized should not carry structural issues by themselves, but the entire social institutions such as government, religion, media, and education should collaborate to solve social ills through more funding, research, and resources.

In conclusion, the Mini $\mathrm{U}$ brochures are one piece of an advertising tool for a small program at the UM, which in turn represents a small part of the entire Canadian 
society, but it reveals the whole social processes of how hidden racial exclusion is subtly circulated and constructed. The brochures as an advertising tool serve as an ideal forum to project a dominant imagery of White people via both online and in print in that they retell a dominant story of whiteness, thus furthering social exclusion of non-Whites. What becomes clear is that the negative symptoms of postcolonialism are still lingering on our campus through skewed Mini U publication practices. Thus, what we need is to call for transformative actions from below and above to make our campus fair and inclusive for serving all in conjunction with the Canadian government's policy change and actions into a more inclusive multicultural society. As a small step, it starts with changing the publication practices of the Mini $\mathrm{U}$ brochure for children, youth, and adults towards a socially just and sustainable campus.

\section{References}

Abdelhameed, I. M. (2016). Social justice in development studies literature: Historical concept analysis. European Journal of Sustainable Development, 5(4), 41-50.

Andrews, D., \& Giardina, M. (2008). 'Toward a cultural studies that matters'. Cultural Studies Critical Methodologies, 8(4), 395-442.

Baffoe, M., Asimeng-Boahene, L., \& Buster, B. (2014). Their way or no way: "Whiteness" as agent for marginalizing and silencing minority voices in academic research and publication. European Journal of Sustainable Development, 3(1), 13-32.

Barroso, P. (2014, September). Semiocracy and secularization: the power of advertising signs and images in the public spaces. Paper presented at the 12th World Congress of Semiotics, Sofia. Abstract retrieved from http://semio2014.org/en/semiotics-applied-to-marketing-communication

Bennett, T. (2014). Art is always subversive-Aesthetics and politics in early and late Lotman. Paper presented at the 12th World Congress of Semiotics, Sofia. Abstract retrieved from http://semio2014.org/en/anoutline-for-a-theory-of-political-semiotics

Bradbury, S. (2011). 'Racisms, resistance and new youth inclusions: the socio-historical development and shifting focus of black, Asian and minority ethnic football clubs in Leicester. In Burdsey, D. (Ed.), Race, ethnicity and football: Persisting debates and emergent issues (pp. 67-83). Abingdon, UK: Routledge.

Campbell, D. G. (2012). The cultivation of racism. Academic Questions, 25(3), 389-393. doi:10.1007/s12129012-9310-y

Cannella, G. S., \& Lincoln, Y. S. (2013). Ethics, research regulations, and critical social science. In N. K. Denzin \& Y. S. Lincoln (Eds.), The landscape of qualitative research: Theories and issues (4th ed., pp. 169187). Thousand Oaks, USA: SAGE.

Clark, D., Kleiman, S., Spanierman, L., Isaac, P., Poolokasingham, G., \& Worthington, R. L. (2014). "Do you live in a teepee?" Aboriginal students' experiences with racial microaggressions in Canada. Journal of Diversity in Higher Education, 7(2), 112-125.

Coté, J. (2009). Education and the colonial construction of whiteness. Australian Critical Race and Whiteness Studies Association Journal, 5(1), 1-14.

Creswell, J. W. (2013). Qualitative inquiry and research design: Choosing among five approaches. Los Angeles, USA: SAGE.

Douglas, D. D., \& Halas, J. M. (2013). The wages of whiteness: Confronting the nature of ivory tower racism and the implications for physical education. Sport, Education and Society, 18(4), 453-474.

Dragan, N. S. (2014). From Alberti's window to today's interface. A semiotic reading of the seeing metaphor in the political discourse. Paper presented at the 12th World Congress of Semiotics, Sofia. Abstract retrieved from http://semio2014.org/en/an-outline-for-a-theory-of-political-semiotics

Fletcher, R. (2008). Living on the edge: The appeal of risk sports for the professional middle class. Sociology of Sport Journal, 25, 310-330.

Freund, A. (2015). Transnationalizing home in Winnipeg: Refugees' stories of the places between the "Hereand-there". Canadian Ethnic Studies, 47(1), 61-86. 
Gourlay, L. (2010). Multimodality, visual methodologies and higher education. In M. Savin-Badan \& C. H. Major (Eds.), New approaches to qualitative research: Wisdom and uncertainty (pp. 80-89). London, UK: Routledge.

Guo, S. (2015). "The colour of skill: Contesting a racialised regime of skill from the experience of recent immigrants in Canada." Studies in Continuing Education, 37(3), 236-250.

Guo, S., \& Lloyd, W. (2015). Revisiting multiculturalism in Canada: Theories, practices, and debates. Rotterdam, the Netherlands: Sense Publishers.

Gyepi-Garbrah, J., Walker, R., \& Gercea, J. (2014). Indigeneity, immigrant newcomers and interculturalism in Winnipeg, Canada. Urban Studies, 51(9), 1795-1811.

Halas, J., McRae, H., \& Carpenter, A. (2012). The quality and cultural relevance of physical education for Aboriginal youth: Challenges and opportunities. In J. Forsyth \& A. R. Giles (Eds.), Aboriginal peoples and sport in Canada: Historical foundations and contemporary issues (pp. 182-205). Vancouver, Canada: UBC Press.

Halas, J., McRae, H., \& Petherick, L. (2012). Advice for physical education teachers from Aboriginal youth: Become an ally. Physical and Health Education Journal, 78(3), 6-11.

Harrison, A. K. (2013). Black skiing, everyday racism, and the racial spatiality of whiteness. Journal of Sport \& Social Issues, 37(4), 315-339.

Harwood, S. A., Choi, S., Orozco, M., Browne, H. M., \& Mendenhall, R. (2015). Racial microaggressions at the University of Illinois at Urbana-Champaign: Voices of students of color in the classroom. University of Illinois at Urbana-Champaign.

Hay, R. (2011). Ethnicity, structure and globalization: An argument about association football in Australia, 1958-2010. Sport in Society, 14(6), 833-850.

Henry, F., \& Tator, C. (2006). The colour of democracy: Racism in Canadian society (3rd ed.). Toronto, Canada: Thomson Nelson.

Henry, F., \& Tator, C. (2009). Racism in the Canadian University. Toronto, Canada: University of Toronto Press.

hooks, b. (1990). Yearning: Race, gender and cultural politics. Toronto, Canada: Between The Line Press.

Hunter, W. C. (2013). China's chairman Mao: A visual analysis of Hunan province online destination image. Tourism Management, 34, 101-111.

Hylton, K. (2009). 'Race' and sport: Critical race theory. New York, USA: Routledge.

Institute for Canadian Citizenship. (2014). Playing together-New citizens, sports, \& belonging. Ottawa, Canada.

Joseph, J., Darnell, S.C., \& Nakamura, Y. (Eds.) (2012). Race and sport in Canada: Intersecting inequalities. Toronto, Canada: Canadian Scholars Press.

Kincheloe, J. L., \& McLaren, P. (2008). Rethinking critical theory and qualitative research. In N.K. Denzin \& Y.S. Lincoln (Eds.), The landscape of qualitative research (3rd ed., pp. 403-456). Thousand Oaks, USA: SAGE.

Kirby, S. L., Greaves, L., \& Reid, C. (2006). Experience research social change: Methods beyond the mainstream (2nd ed.). Peterborough, Canada: Broadview Press.

Lefebvre, H. (1991). The production of space. Oxford, UK: Blackwell.

Lincoln, Y. S., Lynham, S. A., \& Guba, E. G. (2013). Paradigmatic controversies, contradictions, and emerging confluences, Revisited. In N. K. Denzin \& Y. S. Lincoln (Eds.), The landscape of qualitative research: Theories and issues (4th ed., pp. 199-266). Thousand Oaks, USA: SAGE.

Lotman Y. (1979). Culture as collective intellect and the problems of artificial intelligence. In L. M. O'Toole \& A. Shukman (Eds.), Dramatic Structure: Poetic and Cognitive Semantics (pp. 84-96). Oxford, UK: Holdan Books.

Lotman, J. (2009). Culture and explosion. Berlin, Germany: De Gruyter.

Lynn, N., \& Lea, S. J. (2005). Through the looking glass: Considering the challenges visual methodologies raise for qualitative research. Qualitative research in Psychology, 2(3), 213-225.

Marshall, C., \& Rossman, G. B. (2011). Designing qualitative research (5th ed.). Los Angeles, USA: SAGE.

Mauro, M. (2013). A team like no 'other': the racialized position of Insaka FC in Irish schoolboy football. Soccer \& Society, 14(3), 344-363.

Mayring, P. (2014). Qualitative content analysis. Theoretical foundation, basic rand software solution.

Mensah, J., \& Williams, C. J. (2015). Seeing/being double: How African immigrants in Canada balance their ethno-racial and national identities. African and Black Diaspora: An International Journal, 8(1), 39-54. 
Methven, E. (2014, August 5). Racist rants and viral videos: Why the law alone can't end racism. The Conversation. Retrieved from http://theconversation.com/racist-rants-and-viral-videos-why-thelaw-alone-cant-end-racism-30107

Oliver, M. (1992). Changing the social relations of research production? Disability, Handicap \& Society, 7(2), 101-114.

Ricatti, F., \& Klugman, M. (2013). 'Connected to something': Soccer and the transnational passions, memories and communities of Sydney's Italian migrants. The International Journal of the History of Sport, 30(5), 469-483.

Rich, K., Misener, L., \& Dubeau, D. (2015). "Community cup, we are a big family": Examing social inclusion and acculturation of newcomers to Canada through a participatory sport event. Social inclusion, 3(3), 129-141.

Ross, H. H, \& Edwards, W. H. (2016). African American faculty expressing concerns: Breaking the silence at predominantly white research oriented universities. Race, Ethnicity and Education, 19(3), 461-479.

Satzewich, V. (2010). Measuring racism: A case for verstehen. Canadian Journal for Social Research, 6(1), 45-57.

Shendruk, A. (2014, July 14). Soccer vs. hockey: Who plays what in Canada. A staggering number of Canadian kids play soccer. Macleans. Retrieved from http://www.macleans.ca/society/the-goodol-soccer-game/

Silverman, D. (2004). Interpreting qualitative data: Methods for analyzing talk, text and interaction (2nd ed.). London, UK: SAGE.

Smith, A. (2015). Rethinking the 'everyday' in 'ethnicity and everyday life'. Ethnic and Racial Studies, 38(7), 1137-1151.

Suvorov, N., \& Suvorova, I. (2016). Peace, love, harmony and perfection are the basic components of holistic sustainable development of the nations and civilization. European Journal of Sustainable Development, 5(3), 383-396.

Tator, C., \& Henry, F. (2010). The struggle for anti-racism inclusion, and education in the Canadian academy: Representation is not enough. In. Smith, C. (Ed.), Anti-racism in education missing in action (pp. 327-341). Alberta, Canada: Canadian Centre for Policy Alternatives.

Ugolotti, N. M. (2015). Climbing walls, making bridges: Children of immigrants' identity negotiations through capoeira and parkour in Turin. Leisure Studies, 34(1), 19-33.

University of Manitoba. (2014). Taking our place: University of Manitoba strategic plan 2015-2020. Manitoba, Canada.

Veronis, L. (2015). Immigrants' narratives of inclusion and belonging in the transborder city of OttawaGatineau, Canada's national capital region. Canadian Ethnic Studies, 47(2), 45-65.

Walker, G. J., \& Wang, X. (2008). The meaning of leisure for Chinese/Canadians. Leisure Sciences, 31(1), 1-18.

Wolcott, S. (1994). Writing up qualitative research. Newbury Park, USA: SAGE.

Zaami, M. (2015). 'I fit the description': Experiences of social and spatial exclusion among Ghanaian immigrant youth in the Jane and Finch Neighbourhood of Toronto. Canadian Ethnic Studies, 47(3), 69-89.

Zenenga, P. (2012). Visualizing politics in African sport: Political and cultural constructions in Zimbabwean soccer. Soccer \& Society, 13 (2), 250-263. 